\title{
El ozono intrarticular modula la inflamación, mejora el dolor, la rigidez, la función y tiene un efecto anabólico sobre la artrosis de rodilla: estudio cuasiexperimental prospectivo tipo antes-después, 115 pacientes
} Intra-articular ozone modulates inflammation, ameliorates pain and stiffness, improves function and has anabolic effect on knee osteoarthritis: a prospective quasiexperimental before-and-after study, 115 patients

M. E. Fernández-Cuadros, O. Pérez-Moro, M. J. Albaladejo-Florin y S. Álava-Rabasa

Servicio de Rehabilitación y Medicina Física, Hospital Universitario Santa Cristina. Madrid, España

\section{ABSTRACT}

Purpose: The objective of the present study is to verify for the first time in the literature the symptomatic and modifying disease effect of ozone $\left(\mathrm{O}_{2}-\mathrm{O}_{3}\right)$ through clinical (pain, function and stiffness), biochemical (C-reactive protein [CRP], erythrocyte sedimentation rate [ESR], uric acid) and radiological improvement (minimum medial and lateral joint space) in a series of patients with osteoarthritis of the knee.

Methods: A prospective quasi-experimental beforeand-after study was performed in 115 patients with knee osteoarthritis Kellgren-Lawrence grade 2 or more. The ozone protocol consisted of 4 sessions (one session / week) of an intra-articular injection of $20 \mathrm{ml}$ of a medical mixture of Oxygen-Ozone $\left(95-5^{\circ} \mathrm{C}\right.$ ) at a concentration of $20 \mu \mathrm{g} / \mathrm{ml}$. Outcome variables included clinical (pain, stiffness, and function), biochemical (CRP, ESR, uric acid), and radiological variables (minimal femorotibial joint space).

Results: Mean age of the patients was $64.81 \pm$ 11.22 years. Female patients accounted for $75.6 \%$ ( $\mathrm{n}=87$ ), with a female / male ratio of $3: 1$.

Biochemical-variables: CRP decreased from $0.42 \pm$ $0.54 \mathrm{mg} / \mathrm{dL}$ to $0.31 \pm 0.33 \mathrm{mg} / \mathrm{dL}(p=0.0142)$.

Fernández-Cuadros ME, Pérez-Moro O, Albaladejo-Florin MJ, ÁlavaRabasa S. El ozono intrarticular modula la inflamación, mejora el dolor, la rigidez, la función y tiene un efecto anabólico sobre la artrosis de rodilla: estudio cuasiexperimental prospectivo tipo antes-después, 115 pacientes. Rev Soc Esp Dolor 2020;27(2):78-88

\section{RESUMEN}

Objetivo: El objetivo del presente estudio es verificar por primera vez en la literatura el efecto sintomático y modificador de enfermedad del ozono $\left(\mathrm{O}_{2}-\mathrm{O}_{3}\right)$ mediante la mejoría clínica (dolor, función y rigidez), bioquímica (proteína C-reactiva [PCR], velocidad de sedimentación globular [VSG], ácido úrico) y radiológica (mínimo espacio articular medial y lateral) en una serie de pacientes con artrosis de rodilla.

Material y métodos: Se realizó un estudio cuasiexperimental prospectivo tipo antes y después a 115 pacientes con artrosis de rodilla con KellgrenLawrence grado 2 o más. El protocolo de ozono consistió en 4 sesiones (una sesión/semana) de una infiltración intrarticular de $20 \mathrm{ml}$ de una mezcla médica de oxígeno-ozono (95-5\%) a una concentración de $20 \mu \mathrm{g} / \mathrm{ml}$. Las variables de resultado incluyeron variables clínicas (dolor, rigidez y función), bioquímicas (PCR, VSG, ácido úrico) y radiológicas (mínimo espacio articular femorotibial).

Resultados: La edad media de los pacientes fue de $64.81 \pm 11.22$ años. Los pacientes femeninos representaron el $75.6 \%(n=87)$, con una relación mujer/ hombre de 3:1.

Recibido: 28-10-2019

Aceptado: 16-02-2020

Correspondencia: Marcos Fernández-Cuadros Correo electrónico: marcosefc@hotmail.com 
ESR decreased from $14.52 \pm 10.14 \mathrm{~mm} / \mathrm{h}$ to 13.08 $\pm 8.78 \mathrm{~mm} / \mathrm{h}(\mathrm{p}=0.0014)$. Serum uric acid decreased from $5.12 \pm 1.22 \mathrm{mg} / \mathrm{dL}$ to $5.05 \pm 1.24$ ( $\mathrm{p}=0.1307$ ).

Clinical variables: Ozone $\left[\mathrm{O}_{2}-\mathrm{O}_{3}\right]$ significantly improved pain, stiffness and function clinical variables $(p=0.0000)$. Pain measured by VAS was $7.11 \pm 1.11$ points and decreased significantly to $3.56 \pm 1.56$ points $(p=0.0000$ ). Before the intervention, WOMAC-pain subscale was $14.3 \pm 22.29$ points and decreased to $7.13 \pm 33.13$ points $(p=0.0000)$, WOMAC-stiffness subscale was $2.73 \pm 1.39$ points and decreased to $1.16 \pm 1.13$ points $(p=0.0000)$, WOMAC-function subscale was $41.66 \pm 8,1$ points and improved to $25.29 \pm 9.72$ points $(p=0.0000)$.

Radiological variables: In 53 patients analyzed radiologically (according to standardized protocol) at one year of follow-up after ozone treatment, the internal compartment increased significantly from $4.12 \pm 1.41 \mathrm{~mm}$ to $4.4 \pm 1.35 \mathrm{~mm}$ ( $p=0.0008$ ) and the external compartment increased from $6 \pm 1.37$ to $6.16 \pm$ $1.4 \mathrm{~mm}$ ( $\mathrm{p}=0.0753$ ).

Conclusions: Intra articular ozone has demonstrated a symptomatic and disease modifying effect in patients with osteoarthritis of the knee, improving pain, function and stiffness; decreasing markers of inflammation (CRP, ESR and uric acid), and increasing the minimal joint space of the medial and lateral component evidenced radiologically. In this study it has been shown that ozone modulates inflammation, decreases pain and stiffness, improves function and has an anabolic effect in patients with osteoarthritis of the knee. No adverse effect has been observed after intra articular infiltrations of ozone.

Key words: Ozone, biomarkers, pain, WOMAC, osteoarthritis, knee.
Variables bioquímicas: la PCR disminuyó de 0.42 $\pm 0.54 \mathrm{mg} / \mathrm{dl} \mathrm{a} 0.31 \pm 0.33 \mathrm{mg} / \mathrm{dl}$ ( $\mathrm{p}=0.0142$ ). La VSG disminuyó sus valores desde $14.52 \pm 10.14$ $\mathrm{mm} / \mathrm{h}$ hasta $13.08 \pm 8.78 \mathrm{~mm} / \mathrm{h}(\mathrm{p}=0,0014)$. El ácido úrico en suero disminuyó su valor de $5.12 \pm 1.22$ $\mathrm{mg} / \mathrm{dl}$ a $5.05 \pm 1.24$ ( $p=0.1307)$.

Variables clínicas: el ozono $\left(\mathrm{O}_{2}-\mathrm{O}_{3}\right)$ mejoró significativamente las variables clínicas dolor, rigidez y función $(p=0.0000$ ). El dolor medido por EVA fue de $7.11 \pm$ 1.11 puntos y disminuyó significativamente a $3.56 \pm$ 1.56 puntos ( $p=0.0000$ ). Antes de la intervención, la subescala WOMAC-dolor fue de $14.3 \pm 2.29$ puntos y disminuyó a $7.13 \pm 3.13$ puntos $(p=0.0000)$, la subescala WOMAC-rigidez fue de $2.73 \pm 1.39$ puntos y disminuyó a $1.16 \pm 1.13$ puntos $(p=0.0000)$, la subescala WOMAC-función fue de $41.66 \pm 8.1$ puntos y mejoró a $25.29 \pm 9.72$ puntos $(p=0.0000)$.

Variables radiológicas: en 53 pacientes analizados radiológicamente (según protocolo estandarizado) al año de seguimiento después del tratamiento con ozono, el compartimento interno aumento significativamente de $4.12 \pm 1.41 \mathrm{~mm}$ a $4.4 \pm 1.35 \mathrm{~mm}$ ( $p=0.0008$ ) y el compartimento externo aumentó de $6 \pm 1.37$ a 6.16 $\pm 1.4 \mathrm{~mm}$ ( $\mathrm{p}=0.0753$ ).

Conclusiones: El ozono intrarticular ha demostrado efecto sintomático y modificador de la enfermedad en los pacientes con artrosis de rodilla, mejorando el dolor, la función y la rigidez; disminuyendo los marcadores de inflamación (PCR, VSG y ácido úrico), y aumentando el mínimo espacio articular del componente medial y lateral evidenciado radiológicamente. En este estudio se ha evidenciado que el ozono modula la inflamación, disminuye el dolor y la rigidez, mejora la función y tiene efecto anabólico en los pacientes con artrosis de rodilla. No se ha observado ningún efecto adverso tras las infiltraciones intrarticulares de ozono.

Palabras clave: Ozono, biomarcadores, dolor, WOMAC, artrosis, rodilla.

\section{INTRODUCCIÓN}

La artrosis es la enfermedad articular más prevalente. Afecta a casi 4 millones de personas y origina el $50 \%$ de las discapacidades totales en España. La artrosis afecta la calidad de vida de las personas que la padecen en los aspectos físicos, emocionales y sociales. El impacto económico es tal que el coste directo de la artrosis en España es de 4,738 millones de euros/año y representa el 0,5\% del producto interior bruto (1).

La rodilla sana está compuesta por cartílago articular, hueso subcondral, tejido sinovial y cápsula articular. En la artrosis de rodilla hay destrucción del cartílago articular con estrechamiento del espacio articular, esclerosis de hueso subcondral y formación de osteofitos y quistes subcondrales; características que se tienen en cuenta para clasificar radiológicamente la artrosis de rodilla y su severidad $[1,2]$.
La artrosis no tiene cura y su etiología es multifactorial. Los objetivos de tratamiento en el corto plazo son mejorar el dolor, la función y la calidad de vida; y en el largo plazo es retrasar/revertir la destrucción articular. El tratamiento conservador incluye medidas higiénico-dietéticas, analgésicos, AINE, condroitín sulfato/glucosamina, infiltraciones (corticoides, ácido hialurónico, PRP). El tratamiento quirúrgico definitivo incluye la artroplastia total de remplazo, el cual tiene una tasa de éxito del $95 \%$ a los 10 años, aunque esta técnica no está exenta de riesgos y complicaciones [2]. Existe controversia en cuanto al efecto sintomático y modificador de enfermedad de los tratamientos conservadores, tales como el condroitín sulfato/glucosamina $[3,4]$.

Recientemente se ha relacionado la artrosis con la inflamación crónica de bajo grado, pues se cree que el daño oxidativo crónico está implicado en los cambios y 
la progresión de la artrosis de rodilla. Según autores como Atías y cols., Weinstein y cols. y Borreli y cols., el estrés oxidativo crónico desempeña un papel tan importante en la artrosis de rodilla que el futuro del tratamiento dependerá de la supresión del daño oxidativo sin lesionar los mecanismos de defensa antioxidantes del organismo [2]. En este sentido, sería de gran valor terapéutico actuar sobre la modulación y regulación de la inflamación para disminuir la progresión de la artrosis. Además, el tratamiento futuro de la artrosis deberá tratar de disminuir la destrucción del cartílago y favorecer la reparación articular. Por lo tanto, el objetivo principal en el manejo de la artrosis debería ser actuar sobre un gran número de biomarcadores $\mathrm{y} / \mathrm{o}$ citoquinas proinflamatorias producidas en la articulación afectada [2].

Los factores de riesgo para la artrosis incluyen la obesidad, los traumatismos, los factores biomecánicos y la inflamación crónica de bajo grado $(1,5)$. Varios estudios y años de experiencia han demostrado que el ozono $\left(\mathrm{O}_{2}-\mathrm{O}_{3}\right)$ es capaz de modular la inflamación y el dolor en los pacientes con artrosis de rodilla [5]. Además, el ozono $\left[\mathrm{O}_{2}-\mathrm{O}_{3}\right]$ presenta efectos anabólicos que podrían modificar la historia natural de la enfermedad en los pacientes con artrosis de rodilla (5).

Para el manejo de la artrosis de rodilla es necesario utilizar biomarcadores para el diagnóstico, monitorización y progresión de la enfermedad. Estos biomarcadores deberían evaluar resultados clínicos (dolor, rigidez, función), bioquímicos (proteína C-reactiva [PCR], velocidad de sedimentación globular [VSG], ácido úrico, interleucinas) y radiológicos (mínimo espacio articular femorotibial) $(6,7)$. Sin embargo, y hasta donde sabemos, no existe ningún estudio que haya valorado la efectividad del ozono en la artrosis de rodilla teniendo en cuenta los biomarcadores analíticos/bioquímicos ni radiológicos, sino tan solo los biomarcadores clínicos.
El objetivo del presente estudio es verificar por primera vez en la literatura el efecto sintomático y modificador de enfermedad del ozono $\left[\mathrm{O}_{2}-\mathrm{O}_{3}\right]$ mediante la mejoría clínica (dolor, función y rigidez), bioquímica (PCR, VSG] y radiológica (mínimo espacio articular medial y lateral) en una serie de pacientes con artrosis de rodilla.

\section{MATERIAL Y MÉTODOS}

Se realizó un estudio cuasiexperimental prospectivo tipo antes y después. Se incluyeron en el estudio a 115 pacientes con artrosis de rodilla con Kellgren-Lawrence (KL) grado 2 o más, que asistieron al Hospital Universitario de Santa Cristina, con síntomas clínicos (dolor, rigidez, pérdida de la función), que requieren tratamiento conservador y en los que fracasó el tratamiento sintomático previo. El estudio se realizó de enero del 2016 a abril del 2019 y fue autorizado por el Comité de Ética del Hospital Universitario de Santa Cristina, previa firma de consentimiento informado (Figura 1).

Criterios de inclusión: 1] pacientes con artrosis de rodilla con una clasificación de $\mathrm{KL} 2^{\circ}$ o más; 2) con dolor superior a 3 en la escala visual analógica (EVA); 3) en los que haya fallado algún otro tratamiento conservador (AINE, rehabilitación o terapia física); 4) no está dispuesto o no es candidato para artroplastia de rodilla de reemplazo, 5) consentimiento informado debidamente firmado.

Criterios de exclusión: 1] alergia al ozono $\left[\mathrm{O}_{2}-\mathrm{O}_{3}\right](1)$; 2) análisis bioquímico incompleto, ya sea PCR , VSG o ácido úrico; 3] protocolo incompleto de tratamiento; 4] ausencia de alguno de los cuestionarios aplicados (EVA - Western Ontario and Mc Master Index for Osteoarthritis [WOMAC]); 5] ausencia de radiografía de rodilla antes del tratamiento y/o al año de seguimiento; 6) pacientes con favismo [déficit de enzima glucosa

\begin{tabular}{|l|}
\hline Evaluación inicial \\
Consentimiento \\
informado \\
EVA inicial \\
WOMAC inicial \\
Bioquímica inicial \\
Radiografía inicial \\
\hline
\end{tabular}

Protocolo de ozonoterapia
$[\mathrm{n}=115]$
4 sesiones de ozonoterapia
(20 ml de una mezcla de oxígeno-ozono
$95-5 \%$, a una concentración $20 \mu \mathrm{g} / \mathrm{ml}]$
1 sesión/semana

\begin{tabular}{|} 
Evaluación final \\
EVA final \\
WOMAC final \\
Bioquímica final \\
Radiografía final \\
(12 m seguimiento $]$ \\
\hline
\end{tabular}

Estudio prospectivo cuasiexperimental tipo antes-y-después

Fig. 1. Diseño del estudio cuasiexperimental prospectivo tipo antes-después ( $n=115$ ). EVA: escala visual analógica. m: meses. WOMAC: Western Ontario and Mc Master Index for Osteoarthritis. El estudio se realizó de enero del 2016 a abril del 2019. 
6-fosfato deshidrogenasa), por ser contraindicación absoluta para tratamiento con ozono.

Objetivo principal: 1] valorar el efecto sintomático y modificador de enfermedad del ozono mediante variables clínicas, bioquímicas y radiológicas.

Objetivos secundarios: 1] valorar las variables clínicas dolor, rigidez y función mediantes las escalas EVA y WOMAC; 2) valorar las variables bioquímicas PCR, VSG y ácido úrico; 3) valorar las variables radiológicas cambio del espacio tibiofemoral del compartimento medial y lateral.

En la evaluación inicial se explicaron los objetivos del tratamiento, el procedimiento, las indicaciones y las contraindicaciones, se realizaron la evaluación bioquímica inicial (análisis de PCR, VSG y ácido úrico), la radiografía inicial de rodillas, se proporcionaron las escalas de resultado clínico (EVA y WOMAC) y se firmó el consentimiento informado (Figura 1). No valoramos la movilidad articular en este estudio, porque no estaba considerada como variable de resultado.

El protocolo de ozono consistió en 4 sesiones (una sesión/semana) de una infiltración intrarticular de $20 \mathrm{ml}$ una mezcla médica de oxígeno-ozono (95-5\%) a una concentración de $20 \mu \mathrm{g} / \mathrm{ml}$. La piel a infiltrar se limpió con clorhexidina al $1 \%$ y se anestesió con cloruro de etilo. El generador médico utilizado fue Ozonosan $\alpha$-plus ${ }^{\oplus}$. Este equipo proporcionó un volumen de $20 \mathrm{ml}$ de $95-5 \%$ de mezcla de oxígeno y ozono que se introdujo en una jeringa recubierta de silicona de $20 \mathrm{ml}$ de 3 cuerpos. Se utilizó una aguja Quincke de 27G, $4 \mathrm{~cm}$ para administrar el ozono $\left(\mathrm{O}_{2}-\mathrm{O}_{3}\right)$ en la articulación.

Una vez que el paciente se acostó en la camilla, la mezcla médica de ozono $\left(\mathrm{O}_{3}-\mathrm{O}_{3}\right)$ se infiltró en la rodilla en el lado superior y lateral de la rótula. Inmediatamente después de la infiltración se realizó movimientos de flexoextensión de rodilla para favorecer la distribución del ozono en la articulación, escuchándose el característico signo de crepitación intrarticular (maniobra de Pérez-Moro) $(1,6,7)$. En caso de que la infiltración no se realizara en la articulación, no se escuchaba crepitación en la misma, y aparecía enrojecimiento y dolor después de la infiltración; sin embargo, estas quejas desaparecían en unos pocos minutos. Los autores del estudio realizaron las infiltraciones del protocolo de tratamiento.

Después de realizar 4 sesiones del protocolo de ozono $\left(\mathrm{O}_{2}-\mathrm{O}_{3}\right)$, se realizó la evaluación final, se aplicaron análisis de biomarcadores, escalas EVA y WOMAC, y se registraron los efectos adversos (si los hubiera). Los niveles séricos de PCR, VSG y ácido úrico se midieron al inicio del estudio y al final del tratamiento de protocolo.

Para realizar el análisis de los marcadores bioquímicos de inflamación (PCR, VSG y ácido úrico), se tomaron aproximadamente $8 \mathrm{ml}$ de sangre venosa mediante punción venosa del brazo en un vial estéril. Se recogieron $5 \mathrm{ml}$ de sangre en un tubo sin anticoagulante y se separó el suero mediante centrifugación a 3500 rpm durante 20 min. El nivel de PCR en suero se determinó mediante el ensayo MULTIGENT CRP Vario (CRP VARIO, Italia). La concentración mínima medible de PCR es aproximadamente $0,2 \mathrm{mg} / \mathrm{dl}$ y su coeficiente de variación es 5,8-6,3 \% [6]. La determinación del ácido úrico en suero se realizó mediante el uso de 3P39-41 Uric Acid Reagent Kit ${ }^{\circledR}$ (de Abbot, EE. UU.). El coeficiente de variación de esta determinación es 3,6 \% [7].
El resto de la muestra de sangre $(3 \mathrm{ml}$ ) se recogió en otro tubo estéril que contenía anticoagulante EDTA de potasio para medir la VSG mediante el sistema automatizado Ves-Matic Cube 30 (Diese, Italia); aunque el método de Westergren es el método de referencia [6].

Para clasificar radiológicamente la artrosis de rodilla, se utilizó la escala KL. Los grados de KL se definen de la siguiente manera: $0^{\circ}$ ) sin cambios radiológicos; $1^{\circ}$ ) osteofitos dudosos; $2^{\circ}$ l los osteofitos están presentes; $3^{\circ}$ ) Se observa estrechamiento del espacio articular; $4^{\circ}$ ) Presencia de pinzamiento, esclerosis subcondral, geodas subcondrales y osteofitos marginales $[8,9]$. La escala KL es la más usada para clasificar radiológicamente la artrosis de rodilla y constituye un biomarcador de la evolución de la misma $[1,2]$.

Para la evaluación radiográfica de la articulación tibiofemoral medial y lateral, se realizaron radiografías bilaterales anteroposteriores, con ambas piernas apoyadas y completamente extendidas, en carga según protocolo estandarizado (9). Todas las imágenes radiográficas se adquirieron digitalmente mediante un sistema de comunicación de archivo de imágenes (PACS). Se evaluó a 53 pacientes de los 115 que cumplieron un año de seguimiento tras la primera infiltración. Se midió la distancia femorotibial en la radiografía en los compartimentos medial y lateral en la distancia percibida como la más estrecha del espacio articular, y utilizando el programa de medición PACS. Todas las evaluaciones fueron llevadas a cabo por un solo autor, con el fin de reducir la variación interobservador, cuyo coeficiente de variación para medidas repetidas es $3-8 \%(9,10)$.

La severidad de los síntomas se midió mediante las escalas EVA y WOMAC. La EVA es una escala visual analógica de puntuación de dolor graduada de $\mathrm{O}$ a 10. Un mayor valor está relacionado con un mayor dolor y viceversa [11]. El índice WOMAC es una escala que evalúa el dolor, la rigidez y la función, todo en 24 preguntas. Cada respuesta tiene 5 opciones posibles: ninguna, leve, moderada, severa y extrema. El dolor incluye 5 ítems (calificados de 0-20), rigidez 2 ítems (calificados de 0-8) y función 17 ítems (calificados de 0-68) [11]. Cualquier cambio en las puntuaciones del índice WOMAC superior al $6 \%$ se considera como clínicamente importante. Estos cambios representan, para la subescala WOMAC-dolor 1,2 puntos, para la subescala WOMAC-rigidez 0,5 puntos, y para la subescala WOMAC-función 4,1 puntos (12).

El análisis estadístico se realizó mediante el SPSS ${ }^{\circledR}$ versión 20.0. Se utilizaron frecuencias y porcentajes para evaluar variables cualitativas; mientras que para la evaluación de variables cuantitativas se emplearon medias y la desviación estándar. La prueba T-Student fue la herramienta utilizada para evaluar un cambio antes y después del tratamiento en las variables cuantitativas. El nivel de significación fue del $95 \%(p<0,05)$.

Aunque no fue objeto del estudio, los pacientes fueron sistemáticamente valorados semestralmente, debido a que sabemos que el efecto del tratamiento disminuye a partir de los 6 meses, según nuestra experiencia y estudios publicados previamente por nuestro grupo de estudio $[1,5-9]$ a fin de reiniciar tratamiento en los casos que sean necesarios. 
TABLA I

CARACTERÍSTICAS PRINCIPALES DE LOS PACIENTES QUE PARTICIPARON EN EL ESTUDIO AL INICIO DEL TRATAMIENTO ( $\mathrm{N}=115)$

\begin{tabular}{|c|c|}
\hline Variables & Valor \\
\hline \multicolumn{2}{|l|}{ Demográficas } \\
\hline Edad [años] & $64,81 \pm 11,22$ \\
\hline Sexo femenino, $\mathrm{n}$ (porcentaje) & 87 (75,6 \%) \\
\hline Relación mujeres:hombres & $3: 1$ \\
\hline \multicolumn{2}{|l|}{ Clasificación radiológica artrosis } \\
\hline Artrosis $\mathrm{KL} 2^{\circ}, \mathrm{n}$ (porcentaje) & $71[61,7 \%]$ \\
\hline Artrosis $\mathrm{KL} 3^{\circ}, \mathrm{n}$ (porcentaje) & 34 [29,5\%] \\
\hline Artrosis $\mathrm{KL} 4^{\circ}, \mathrm{n}$ (porcentaje) & $10[8,6 \%]$ \\
\hline \multicolumn{2}{|l|}{ Biomarcadores de inflamación } \\
\hline PCR mg/dl, media \pm desviación estándar & $0,42 \pm 0,54$ \\
\hline VSG mm/h, media \pm desviación estándar & $14,52 \pm 10,14$ \\
\hline Ácido úrico mg/dl, media \pm desviación estándar & $5,12 \pm 1,22$ \\
\hline \multicolumn{2}{|l|}{ Variables clínicas } \\
\hline EVA-dolor, media \pm desviación estándar; rango 0-10 & $7,11 \pm 1,1$ \\
\hline WOMAC-dolor, media \pm desviación estándar; rango 0-20 & $14,3 \pm 2,29$ \\
\hline WOMAC-rigidez, media \pm desviación estándar; rango 0-8 & $2,73 \pm 1,39$ \\
\hline WOMAC-función, media \pm desviación estándar; rango 0-68 & $41,66 \pm 8,1$ \\
\hline \multicolumn{2}{|l|}{ Variables radiológicas } \\
\hline Mínimo espacio articular compartimento medial $(n=53)$ en $\mathrm{mm}$ & $4,12 \pm 1,41$ \\
\hline Mínimo espacio articular compartimento lateral $(\mathrm{n}=53$ ), en $\mathrm{mm}$ & $6 \pm 1,37$ \\
\hline
\end{tabular}

EVA: escala visual analógica. KL: Kellgren-Lawrence. PCR: proteína C-reactiva. VSG: velocidad de sedimentación globular. WOMAC: Western Ontario and Mc Master Index for Osteoarthritis.

\section{RESULTADOS}

En este estudio se evaluaron 115 pacientes. La edad media de los pacientes fue de 64,81 $\pm 11,22$ años. Los pacientes femeninos representaron el $75,6 \%(n=87)$, mientras que los pacientes masculinos correspondieron al $24,4 \%(n=28)$, con una proporción de mujeres: hombres de 3:1 (Tabla I).

El grado radiológico más frecuente fue $\mathrm{KL} 2^{\circ}(\mathrm{n}=71$; $61,7 \%$ ), seguido de $\mathrm{KL} 3^{\circ}$ grado ( $\mathrm{n}=34$; $29.5 \%$ ) y $\mathrm{KL} 4^{\circ}$ grado $(\mathrm{n}=10 ; 8,6 \%$ ) (Tabla I).

Con respecto a las variables de resultado, los biomarcadores de inflamación PCR y VSG disminuyeron significativamente $(p<0,05)$ después de la terapia con ozono $\left[\mathrm{O}_{2}-\mathrm{O}_{3}\right]$. La PCR disminuyó de 0,42 $\pm 0,54 \mathrm{mg} / \mathrm{dl}$ a 0,31 \pm 0,33 mg/dl ( $p=0,0142$ ) (Tabla II). La VSG disminuyó sus valores desde 14,52 $\pm 10,14 \mathrm{~mm} / \mathrm{h}$ hasta 13,08 $\pm 8,78 \mathrm{~mm} / \mathrm{h}(\mathrm{p}=0,0014)$ (Tabla II). El ácido úrico en suero disminuyó su valor de $5,12 \pm 1,22 \mathrm{mg} / \mathrm{dl}$ a $5,05 \pm 1,24$ ( $\mathrm{p}=0,1307$ ) aunque esa disminución no fue estadísticamente significativa (Tabla II).

Con respecto a la gravedad de los síntomas [dolor, rigidez y función) en la artrosis de la rodilla, medida por las escalas EVA y WOMAC, la terapia con ozono $\left[\mathrm{O}_{2}-\mathrm{O}_{3}\right]$ mejoró significativamente todas y cada una de las variables ( $p=0,0000$ ). Antes del tratamiento, el dolor medido por EVA fue de 7,11 $\pm 1,11$ puntos $y$ disminuyó significativamente a 3,56 $\pm 1,56$ puntos ( $p=0,0000$ ) (Tabla II). Antes de la intervención, la subescala WOMAC-dolor fue de 14,3 $\pm 2,29$ puntos y disminuyó a 7,13 $\pm 3,13$ puntos $(p=0,0000)$, la subescala WOMAC-rigidez fue de $2,73 \pm 1,39$ puntos y disminuyó a $1,16 \pm 1,13$ puntos ( $p=0,0000$ ), la subescala WOMAC-función fue de 41,66 \pm 8,1 puntos y mejoró a 25,29 \pm 9,72 puntos ( $p=0,0000$ ) (Tabla II).

Con respecto a las variables radiológicas, al valorar a 53 de los 115 pacientes que cumplieron un año de seguimiento después del tratamiento con ozono, se observó que el compartimento interno aumento significativamente de 4,12 $\pm 1,41 \mathrm{~mm}$ a 4,4 $\pm 1,35 \mathrm{~mm}$ ( $p=0,0008)$ y el compartimento externo aumentó de $6 \pm 1,37$ a $6,16 \pm 1,4 \mathrm{~mm}$ ( $\mathrm{p}=0,0753$ ) (Tabla II). Se presentan 2 casos clínicos como muestra del cambio radiológico en los compartimentos interno y externo (Figuras 2 y 3 ).

No se ha reportado ninguna reacción adversa tras el tratamiento, excepto el dolor tras la infiltración, el cual cedió en pocos minutos. 
TABLA II

EFECTO DEL OZONO INTRARTICULAR SOBRE LAS VARIABLES CLÍNICAS (DOLOR, RIGIDEZ Y FUNCIÓN), LOS BIOMARCADORES DE INFLAMACIÓN (PCR, VSG, ÁCIDO ÚRICO) Y LAS VARIABLES RADIOLÓGICAS (MÍNIMO ESPACIO ARTICULAR MEDIAL Y LATERAL) EN LOS PACIENTES CON ARTROSIS DE RODILLA ( $N=115)$

\begin{tabular}{|c|c|c|c|}
\hline Variables de resultado & Antes & Después & $p$ \\
\hline \multicolumn{4}{|l|}{ Biomarcadores inflamación } \\
\hline PCR mg/dl, media \pm desviación estándar & $0,42 \pm 0,54$ & $0,31 \pm 0,33$ & 0,0142 \\
\hline VSG mm/h, media \pm desviación estándar & $14,52 \pm 10,14$ & $13,08 \pm 8,78$ & 0,0014 \\
\hline Ácido úrico, mg/dl, media \pm desviación estándar & $5,12 \pm 1,22$ & $5,05 \pm 1,24$ & 0,1307 \\
\hline \multicolumn{4}{|l|}{ Variables clínicas } \\
\hline EVA-dolor, media \pm desviación estándar & $7,11 \pm 1,1$ & $3,56 \pm 1,56$ & 0,0000 \\
\hline WOMAC-dolor, media \pm desviación estándar & $14,3 \pm 2,29$ & $7,13 \pm 3,13$ & 0,0000 \\
\hline WOMAC-rigidez, media \pm desviación estándar & $2,73 \pm 1,39$ & $1,16 \pm 1,13$ & 0,0000 \\
\hline WOMAC-función, media \pm desviación estándar & $41,66 \pm 8,1$ & $25,29 \pm 9,72$ & 0,0000 \\
\hline \multicolumn{4}{|l|}{ Variables radiológicas } \\
\hline Mínimo espacio articular compartimento medial ( $n=53$ ), en $\mathrm{mm}$ & $4,12 \pm 1,41$ & $4,4 \pm 1,35$ & 0,0008 \\
\hline Mínimo espacio articular compartimento lateral ( $n=53$ ), en mm & $6 \pm 1,37$ & $6,16 \pm 1,4$ & 0,0753 \\
\hline
\end{tabular}

EVA: escala visual analógica. KL: Kellgren-Lawrence. PCR: proteína C-reactiva. VSG: velocidad de sedimentación globular. WOMAC: Western Ontario and Mc Master Index for Osteoarthritis.

p: prueba estadística T-Student.
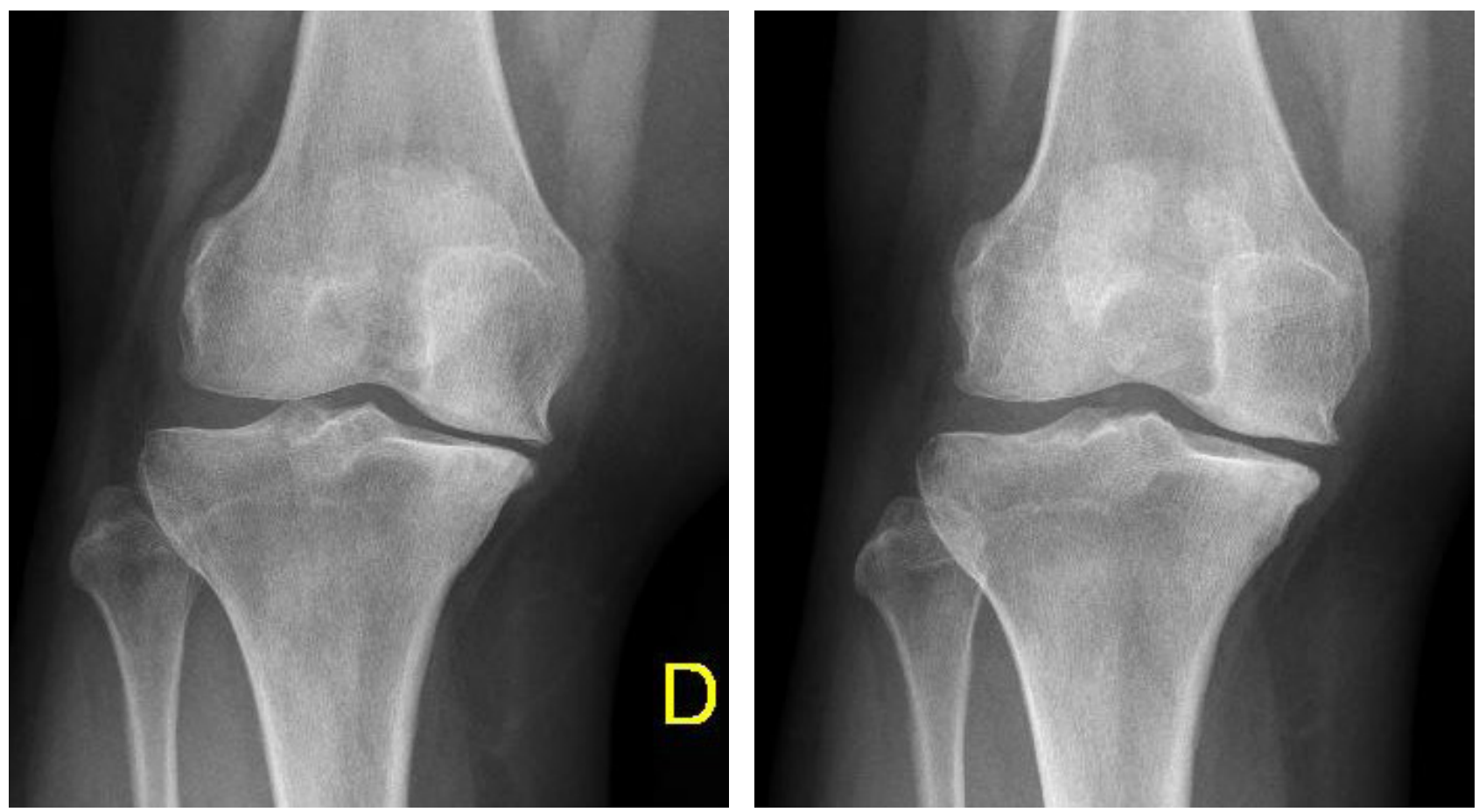

Fig. 2. En una paciente mujer de 67 años, la radiografía de rodilla derecha al inicio y al término de tratamiento (12 meses de seguimiento) demuestra mejoría en el compartimento medial $[0,29 \mathrm{~mm}$ a 0,46 mm). 

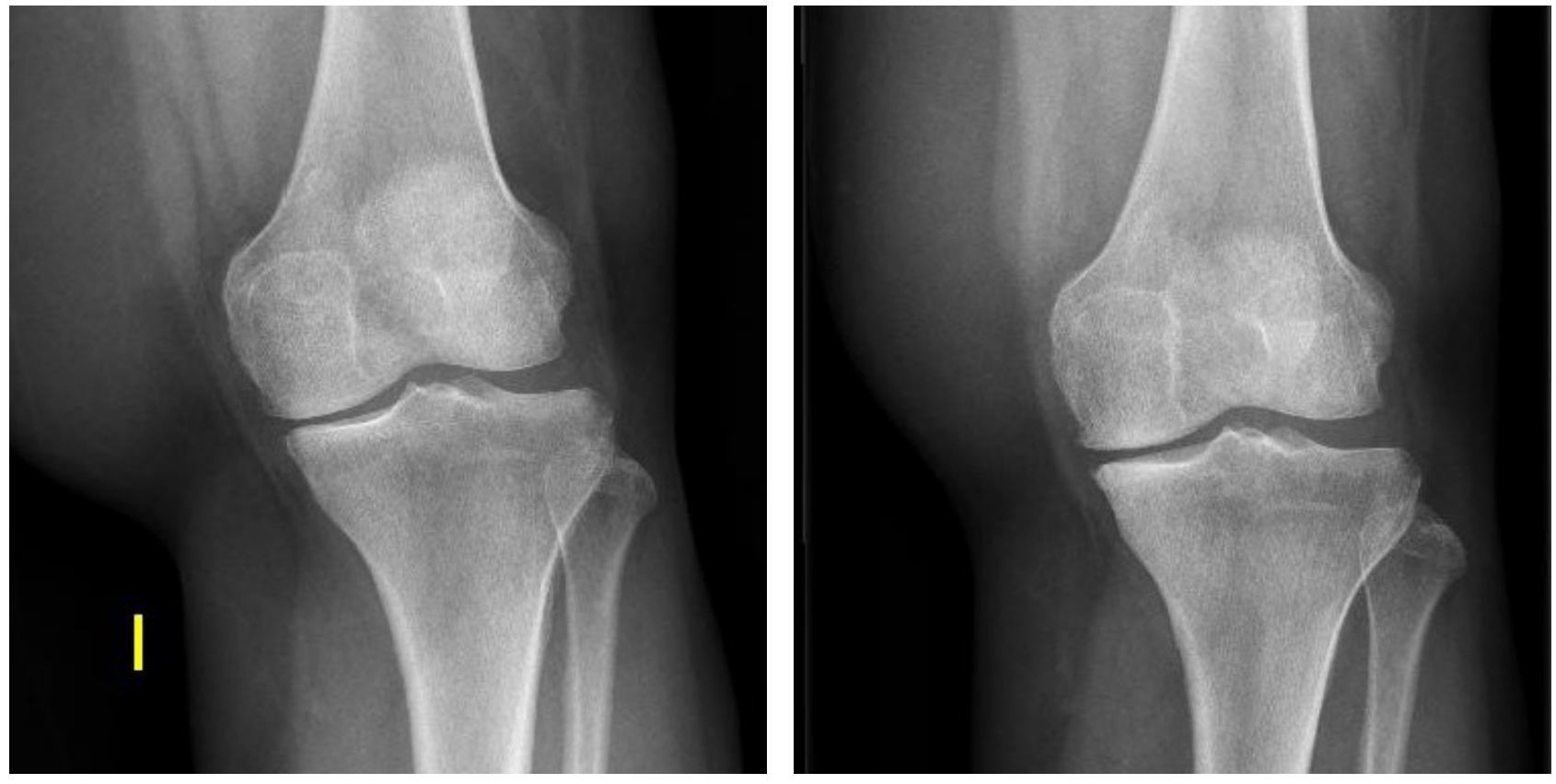

Fig. 3. En una paciente mujer de 67 años, la radiografía de rodilla izquierda al inicio y al término de tratamiento (12 meses de seguimiento) demuestra mejoría en el compartimento medial $[0,34 \mathrm{~mm}$ a $0,40 \mathrm{~mm})$.

\section{DISCUSIÓN}

Hasta donde sabemos, este es el primer artículo que ha demostrado efectividad del ozono $\left(\mathrm{O}_{2}-\mathrm{O}_{3}\right]$ en la artrosis de rodilla, modificando por primera vez biomarcadores clínicos, bioquímicos y radiológicos. Este artículo confirma el efecto sintomático y modificador de la enfermedad de la ozonoterapia intrarticular en una serie de pacientes con gonartrosis.

La artrosis de rodilla es la causa más común de dolor y discapacidad en las sociedades occidentales, como en España [2]. Es tan prevalente que el $50 \%$ de las personas entre 60-75 años presenta algún signo radiológico, y el $80 \%$ de las personas mayores de 80 años tienen signos clínicos y radiológicos $[1,2]$.

La artrosis afecta comúnmente a personas de mediana edad. En los grupos más jóvenes afecta a ambos sexos por igual, pero a partir de los 50 años afecta más a las mujeres, como en nuestro estudio (relación mujer/hombre de 3/1), y con una edad media de 64,81 años $(1,2,5)$.

A día de hoy no existe un tratamiento para la artrosis, por lo que los objetivos de manejo son disminuir los síntomas (dolor, rigidez, disfunción) y disminuir/ralentizar el desgaste y destrucción articular $(1,2)$, objetivos que se han conseguido en los pacientes de este estudio tratados con ozono $\left(\mathrm{O}_{2}-\mathrm{O}_{3}\right)$.

Malathi y cols. sugieren que el desarrollo de la artrosis suele ir acompañada de inflamación [13). Diversos estudios epidemiológicos sugieren que la gravedad y la progresión de la pérdida de cartílago articular tibiofemoral es más frecuente y grave en pacientes con líquido sinovial inflamado (14). En la progresión de la artrosis se encuentran niveles más altos de IL-1 $\beta$ y TNF- $\alpha$, que son mediadores de la inflamación (13). Otros estudios han observado que los niveles elevados de PCR están relacionados con la prevalencia y la progresión de la artrosis de rodilla o cadera (13). Otros autores refieren que los niveles elevados de PCR están relacionados con niveles de IL-6 en el líquido sinovial e infiltración sinovial, así como con síntomas de dolor y rigidez, clasificación radiológica y progresión de la artrosis (15). Muchos otros investigadores en el mundo han sugerido que no solo la IL-6, sino la PCR y la VSG están estrechamente relacionadas con la artrosis radiológica de la rodilla, la gravedad de los síntomas y la progresión de la enfermedad (16-19). Estos biomarcadores indican que la inflamación de bajo grado podría ser un factor involucrado en los cambios estructurales y sintomáticos en la artrosis de rodilla [20]. Además, los datos presentados muestran que los biomarcadores inflamatorios, y en el caso específico de este estudio la PCR y la VSG, podrían ser un factor clave en la patogénesis de la artrosis de la rodilla y podrían servir como predictores y variables de resultado [6].

Con respecto al ácido úrico, varias observaciones epidemiológicas han reportado una asociación del ácido úrico con la inflamación sistémica y con la artrosis. Roddy y Doherty sugieren que la gota y la artrosis comparten un vínculo patogénico común [21]. Ma y Leung afirman que la deposición de cristales de ácido úrico monosódico secundarios a hiperuricemia promueve la degradación directa del cartílago [22]. Martinon y cols. y Denoble y cols., en diferentes estudios, afirman que los cristales de ácido úrico monosódico activan las respuestas inmunes innatas de los macrófagos a través de NALP3 (Natch Domain, Leucin-rich repeat, and pyrin domain containing protein 3 ) activando la caspasa-1 
y liberando IL-1 $\beta$ e IL-18, citoquinas relacionadas con la degradación del cartílago $[23,24)$. Según ellos, la gota y la artrosis compartirían la misma vía inflamatoria [22-24). Varios estudios demográficos en hombres y mujeres sanos demostraron que el ácido úrico sérico se asocia positivamente con la PCR [25]. Un estudio de 957 personas italianas de edad avanzada mostró que el ácido úrico sérico se asocia positivamente no solo con la PCR, sino también con el TNF- $\alpha$ e IL-6 [26]. En otro estudio que incluyó a 608 individuos caucásicos suizos, se encontró que el ácido úrico sérico estaba positivamente asociado a la PCR, el TNF- $\alpha$ y la IL-6 (tanto en hombres como en mujeres] (27). Billiet y cols. mencionaron que el ácido úrico puede estimular la producción de TNF- $\alpha$ en las células sinoviales [28].

Por todas estas consideraciones, tanto la PCR como la VSG y el ácido úrico se consideran como biomarcadores inflamatorios implicados en la patogénesis de la artrosis, y han sido valorados en este estudio.

En una reciente revisión bibliográfica, FernándezCuadros y cols. manifestaron que el ozono $\left(\mathrm{O}_{2}-\mathrm{O}_{3}\right)$ es capaz de modular la inflamación, actuando sobre diversos marcadores de inflamación, inhibiendo citoquinas proinflamatorias, minerometaloproteasas, óxido nítrico, prostaglandina E2 y estimulando citoquinas antiinflamatorias $[1,2]$. Además, Fernández-Cuadros y cols. también han referido que el ozono $\left[\mathrm{O}_{2}-\mathrm{O}_{3}\right]$ es capaz de estimular factores de crecimiento (TGF-1, IGF-1), condrocitos y células madre [1,2]. Por estos motivos, creemos que el ozono $\left(\mathrm{O}_{2}-\mathrm{O}_{3}\right)$ podría modular la inflamación y presentar un efecto anabólico en la artrosis de rodilla, hipótesis que ha quedado demostrada en este estudio.

En nuestro estudio, el ozono $\left(\mathrm{O}_{2}-\mathrm{O}_{3}\right)$ ha sido capaz de disminuir los marcadores de inflamación tales como la PCR (de 0,41 a 0,31 mg \%), la VSG (de 14,52 a $13,08 \mathrm{~mm} / \mathrm{h}$ ) y el ácido úrico (de $5,12 \mathrm{mg} \%$ a $5,05 \mathrm{mg} \%$ ), lo que confirma que el ozono $\left(\mathrm{O}_{2}-\mathrm{O}_{3}\right)$ es capaz de modular la inflamación en pacientes con artrosis de rodilla, disminuyendo estos marcadores de inflamación. Este hallazgo se relaciona con lo recientemente publicado por nuestro grupo de estudio $(6,7)$.

En este estudio, el ozono $\left(\mathrm{O}_{2}-\mathrm{O}_{3}\right)$ ha sido capaz de disminuir el dolor y la rigidez, además de mejorar la función y la calidad de vida, evidenciado por una mejoría en las escalas clínicas EVA y WOMAC, con una duración de efecto de 6 meses. Estos resultados concuerdan con lo reportado previamente por nuestro grupo de estudio $(1,6-8)$. El efecto sintomático del ozono $\left(\mathrm{O}_{2}-\mathrm{O}_{3}\right)$ sobre la artrosis de rodilla queda demostrado en este estudio.

La radiografía suele ser el examen de imagen inicial realizado en pacientes con artrosis de la articulación tibiofemoral. La radiografía también se usa comúnmente en estudios demográficos para definir la presencia de artrosis de la articulación tibiofemoral y para documentar los cambios en la gravedad de la historia de la enfermedad a lo largo del tiempo (1). El cartílago articular se adelgaza e inflama a medida que avanza la artrosis, pero normalmente el grosor del cartílago disminuye con el tiempo en la artrosis de rodilla (2). La progresión es mayor en el compartimento medial en comparación con el compartimento lateral de la articulación tibiofemoral [2]. Sobre la base de este supuesto, existe una correlación moderada entre el estrechamiento del espacio articular y la pérdida de cartílago articular $(2-4,14)$. El estrechamiento del espacio articular se define cuando la anchura mínima del espacio articular es inferior a $3 \mathrm{~mm}$ para la articulación tibiofemoral [29]. Dado que no se observa cartílago en la radiografía, su pérdida se mide indirectamente por el estrechamiento del espacio articular (9). Por lo tanto, la radiografía es un método sin costo para supervisar la progresión de la osteoartritis y, actualmente el "gold estándar", es decir, el método más sencillo y aceptado para evaluar la progresión de la osteoartritis y la destrucción del cartílago (30-35). Un cambio en el mínimo espacio tibiofemoral se considera como una medida primaria del cambio biológico en la artrosis, e indirectamente, un biomarcador para evaluar los tratamientos biológicos en la artrosis [36].

Tras un año de seguimiento con controles radiológicos a 53 de los 115 pacientes del estudio, el ozono $\left(\mathrm{O}_{2}-\mathrm{O}_{3}\right)$ ha sido capaz de aumentar el mínimo espacio articular del compartimento medial (de 4,12 a $4,44 \mathrm{~mm}$ ) y del compartimento lateral (de 6,0 a $6,16 \mathrm{~mm}$ ), revirtiendo la artrosis de rodilla en nuestra serie de casos. Este hallazgo sugiere el efecto modificador de la enfermedad del ozono $\left(\mathrm{O}_{2}-\mathrm{O}_{3}\right)$ sobre la artrosis de rodilla, hallazgos que coinciden con lo reportado recientemente por Fernández-Cuadros y cols. (9).

Hasta donde sabemos, este es el primer artículo que sugiere radiológicamente el efecto anabólico o estructural del ozono sobre la artrosis de rodilla, y por tanto, modificador de la enfermedad. Solo existe un estudio que ha reportado efecto modificador de la enfermedad en la artrosis de rodilla, mediante el uso oral de glucosamina/condroitín sulfato [3], aunque el que se haya reportado en ese estudio que tal tratamiento solo lograra efecto anabólico sobre el compartimento lateral y no en el compartimento medial habla más a favor de la evolución natural de la enfermedad (artrosis) que de una modificación real producida por tales fármacos sobre la artrosis de rodilla [4].

En nuestro estudio, y basado en nuestra experiencia, hemos aplicado en todos los pacientes $20 \mathrm{ml}$ de ozono a una concentración de $20 \mu \mathrm{g} / \mathrm{ml}(1,5-9)$. Es probable que la mayor cantidad de ozono ( $400 \mu \mathrm{g}$ dosis total) haya sido la responsable de la pronta efectividad observada al finalizar el tratamiento (a las 4 semanas), aunque no lo hemos comparado con otro grupo que haya recibido menor volumen o menor dosis/concentración. Es importante destacar que en nuestro estudio hemos aplicado solo 4 sesiones, mientras que otros estudios aplican hasta 8-12 sesiones $(38,39)$. Esto tiene una repercusión económica y logística, dado que los recursos en salud son limitados. En nuestro estudio hemos valorado el dolor, la rigidez y la función por las escalas EVA y WOMAC, como lo hacen la mayoría de los estudio que se conocen hasta el momento [37-40). Además, hemos tratado a pacientes con artrosis de rodilla grados $\mathrm{KL} 2^{\circ}$ a $4^{\circ}$, mientras que la mayoría de los estudios tratan a los pacientes con grado $\mathrm{KL} 1^{\circ}-2^{\circ}$ y $\mathrm{KL} 2^{\circ}-3^{\circ}$ (37-40).

Así pues, en comparación con nuestro estudio, Lopes de Jesús (2017) trató a pacientes con $K L 2^{\circ}-3^{\circ}$, los evaluó con las escalas EVA y WOMAC y aplicó ozono intrarticular, $10 \mathrm{ml} \times 20 \mu \mathrm{g} / \mathrm{ml}, 8$ sesiones (1v/s) (37-40). Reissadat (2018) trató a pacientes con $\mathrm{KL}$ $2^{\circ}-3^{\circ}$, los evaluó con las escalas EVA y WOMAC y aplicó ozono intrarticular, $10 \mathrm{ml} \times 30 \mu \mathrm{g} / \mathrm{ml}$, 3 sesiones 
(1v/s) (37-40). Hashemi (2015) trató a pacientes con $\mathrm{KL} 2^{\circ}-3^{\circ}$, los evaluó con las escalas EVA y WOMAC y aplicó ozono intrarticular, $10 \mathrm{ml} \times 40 \mu \mathrm{g} / \mathrm{ml}$, 8 sesiones ( 3 veces la primera semana, 2 veces la segunda semana y $1 \mathrm{v} / \mathrm{s}$ por 3 semanas) (37-40). Babaei-Ghazani (2018) trató a pacientes con $K L 2^{\circ}-3^{\circ}$, los evaluó con las escalas EVA y WOMAC y aplicó ozono intrarticular, $10 \mathrm{ml} \times 15 \mu \mathrm{g} / \mathrm{ml}, 1$ dosis única $[37,39,40]$. Feng (2017) trató a pacientes con $\mathrm{KL} 3^{\circ}-4^{\circ}$, los evaluó con las escalas EVA y Lysholm y aplicó ozono intrarticular, $20 \mathrm{ml} \times 20 \mu \mathrm{g} / \mathrm{ml}, 12$ sesiones (2v/s por 6 semanas) $[37,39]$. Calunga $(2012)$ trató a pacientes con artrosis de rodilla sin especificar grado $\mathrm{KL}$, los evaluó con la escala EVA y aplicó ozono rectal 20 sesiones, $100-200 \mathrm{ml} \times 25-40 \mu \mathrm{g} / \mathrm{ml}$ y ozono intrarticular, $5-10 \mathrm{ml} \times 30 \mu \mathrm{g} / \mathrm{ml}, 4$ sesiones (2v/s) [37). Duymus (2017) trató a pacientes con $K L 2^{\circ}-3^{\circ}$, los evaluó con las escalas EVA y WOMAC y aplicó ozono intrarticular, $15 \mathrm{ml} \times 30 \mu \mathrm{g} / \mathrm{ml}, 4$ sesiones (1v/s) [37-40). Hashemi (2017) trató a pacientes con artrosis de rodilla sin especificar grado KL, los evaluó con las escalas EVA y valoró los biomarcadores IL-1 $\beta$ y TNF- $\alpha$, y aplicó ozono intrarticular, $5 \mathrm{ml} \times 35 \mu \mathrm{g} / \mathrm{ml}, 1$ dosis única $[37,39]$. Hashemi (2016) trató a pacientes con $\mathrm{KL} 2^{\circ}-3^{\circ}$, los evaluó con la escala EVA y con la escala Oxford Knee Scale y aplicó ozono intrarticular, $10 \mathrm{ml} \times 40 \mu \mathrm{g} / \mathrm{ml}$ y ozono periarticular $5 \mathrm{ml} \times 10 \mu \mathrm{g} / \mathrm{ml}$ por punto, 8 sesiones ( 3 veces la primera semana; 2 veces la segunda semana y $1 \mathrm{v} / \mathrm{s}$ por 3 semanas] [37,39). FernándezCuadros (2018) trató a pacientes con $\mathrm{KL} 2^{\circ}-4^{\circ}$, los evaluó con las escalas EVA y WOMAC y aplicó ozono intrarticular, $20 \mathrm{ml} \times 20 \mu \mathrm{g} / \mathrm{ml}, 4$ sesiones (1v/s) (7,37). Mishra (2011) trató a pacientes con KL $2^{\circ}$, los evaluó con las escalas WOMAC y MacNab modificado y aplicó ozono intrarticular, $10 \mathrm{ml} \times 30 \mu \mathrm{g} / \mathrm{ml}$, 3 sesiones $(1 \mathrm{v} / \mathrm{mes})(38,39)$. Gombini $(2016)$ trató a pacientes con $\mathrm{KL} 2^{\circ}-3^{\circ}$, los evaluó con las escalas EVA y Oxford Knee Scale y aplicó ozono intrarticular, $15 \mathrm{ml} \times 15 \mu \mathrm{g} / \mathrm{ml}, 5$ sesiones (1v/s) (38). Chansoria (2016) trató a pacientes con $K L 1^{\circ}-2^{\circ}$, los evaluó con las escalas EVA y WOMAC y aplicó ozono intrarticular, $5 \mathrm{ml} \times 25 \mu \mathrm{g} / \mathrm{ml}$, una dosis única $(38,39)$. Finalmente, Invernizzi (2017) trató a pacientes con $\mathrm{KL} 2^{\circ}-3^{\circ}$, los evaluó con las escalas EVA y Oxford Knee Scale, SF-12 y EUROQoL y aplicó ozono intrarticular, volumen no especificado a una concentración de $20 \mu \mathrm{g} / \mathrm{ml}, 4$ sesiones $(1 \mathrm{v} / \mathrm{s})(38,39)$. Todos estos estudios han demostrado mejoría clínica del ozono en la artrosis de rodilla, objetivada por las escalas utilizadas, lo que se corresponde con lo observado en nuestro estudio. Solo un estudio (Hashemi 2017) ha valorado las citoquinas proinflamatorias IL-1 $\beta$ y TNF- $\alpha[37,39]$. Ningún estudio ha valorado los biomarcadores PCR, VSG, ácido úrico, ni ha evaluado radiológicamente la evolución tras la ozonoterapia intrarticular (37-40).

En nuestro estudio, el empleo de ozono $\left(\mathrm{O}_{2}-\mathrm{O}_{3}\right)$ intrarticular ha demostrado ser un tratamiento seguro, sin efectos adversos y capaz de mejorar objetivamente biomarcadores clínicos, analíticos y radiológicos. Por lo tanto, coincidimos con Arias-Vazquez y cols., NooriZadeh y cols., Sconza y cols. y Oliviero y cols., quienes en recientes revisiones sistemáticas y metanálisis, además de citar nuestras publicaciones previas [5-8] destacando la importancia, relevancia y actualidad de nuestros hallazgos, creen que el ozono $\left(\mathrm{O}_{2}-\mathrm{O}_{3}\right)$ debe ser considerado como una alternativa terapêutica para el manejo de la artrosis de rodilla, debido a su probada efectividad (37-40).

\section{CONCLUSIÓN}

El ozono intrarticular ha demostrado efecto sintomático y modificador de la enfermedad en los pacientes con artrosis de rodilla, mejorando el dolor, la función y la rigidez; disminuyendo los marcadores de inflamación (PCR, VSG y ácido úrico), y aumentando el mínimo espacio articular del componente medial y lateral evidenciado radiológicamente. En este estudio se ha evidenciado que el ozono modula la inflamación, disminuye el dolor y la rigidez, mejora la función y tiene efecto anabólico en los pacientes con artrosis de rodilla. No se ha observado ningún efecto adverso tras las infiltraciones intrarticulares de ozono.

\section{CONFLICTOS DE INTERESES}

Declaramos la no existencia de conflicto de intereses de ninguno de los autores.

\section{FUENTES DE FINANCIACIÓN}

No existe financiación alguna para la realización de este estudio.

\section{AGRADECIMIENTOS}

A Saturnino Díaz Trujillo, bibliotecario del Hospital Universitario Santa Cristina, Madrid, por la búsqueda bibliográfica para la realización de este estudio. A las auxiliares Aurelia Gómez Sierra y a María del Carmen de la Riva Molina, por el apoyo logístico para la realización de este estudio.

\section{BIBLIOGRAFÍA}

1. Fernández-Cuadros ME, Pérez-Moro OS, Albaladejo-Florín MJ. Ozone fundamentals and effectiveness in knee pain: Chondromalacia and knee osteoarthritis. Germany: Lambert Academic Publishing; 2016.

2. Fernández-Cuadros ME. Análisis de la calidad de vida en pacientes con prótesis de rodilla. Tesis doctoral. Universidad de Salamanca. España. 2013.

3. Raynauld JP, Pelletier JP, Abram F, Dodin P, Delorme P, Martel-Pelletier J. Long-term effects of glucosamine and chondroitin sulfate on the progression of structural changes in knee osteoarthritis: six-year follow-up data from the Osteoarthritis Initiative. Arthritis Care Res (Hobboken). 2016;68(10):1560-6. DOI: 10.1002/acr.22866.

4. Fernández-Cuadros ME. Does glucosamine/chondroitin sulfate have a long-term effect on the progression of structural changes in knee osteoarthritis? Comment on the article by Raynauld et al. Arthritis Care Res (Hobboken). 2018;70(1):167. DOI: 10.1002/acr.23313. 
5. Fernández-Cuadros ME, Perez-Moro OS, Miron-Canelo JA. Could ozone be used as a feasible future treatment in osteoarthritis of the knee. Diversity Equal Health Care. 2016;13(3):232-9.

6. Fernandez-Cuadros ME, Perez-Moro OS, Albaladejo-Florin MJ, Algarra-Lopez R. Ozone decreases biomarkers of inflammation (C-reactive protein and erytrocyte sedimentation rate) and improves pain, function and quality of life in knee osteoarthritis patients: a before-and-after study and review of the literature. Middle East J Rehabil Health Stud. 2018; 5(2):e64507. DOl: 10.5812/mejrh.64507.

7. Fernández-Cuadros ME, Pérez-Moro OS, Albaladejo-Florín MJ, Algarra-Lopez R. Intra articular ozone reduces serum uric acid and improves pain, function and quality of life in knee osteoarthritis patients: a before-and-after study. Middle East J Rehabil Health Stud. 2018;5(3):e68599. DOI: 10.5812/ mejrh.68599.

8. Fernández-Cuadros ME, Pérez-Moro OS, Albaladejo-Florín M, Mirón-Canelo JA. Ozone improves pain, function and quality of life in patients with knee osteoarthritis: A prospective quasi-experimental before-after study. Middle East $J$ Rehabil Health Stud. 2017;4(1):e41821. DOl: 10.17795/ mejrh-41821.

9. Fernández-Cuadros ME, Pérez-Moro OS, Albaladejo-Florín MJ. Knee osteoarthritis: Condroprotector action and symptomatic effect of ozone on pain, function, quality of life, minimal joint space and knee arthroplasty delay. Middle East J Rehabil Health Stud. 2017;4(1):e43200. DOI: 10.17795/ mejrh-43200.

10. Buckland-Wright JC, Macfarlane DG, Williams SA, Ward RJ. Accuracy and precision of joint space width measurements in standard and macroradiographs of osteoarthritic knees. Ann Rheum Dis, 1995;54(11):872-80. DOI: 10.1136/ ard.54.11.872.

11. Pérez-Moro O, Albaladejo-Florín M, Entrambasaguas-Estepa B, Fernández-Cuadros, M. Effectivenness of PRP on pain, function and quality of life in chondromalacia and patellofemoral pain syndrome: A pretest-postest analysis. Nov Tech Arthritis Bone Res. 2017;1(1):1-8.

12. Bellamy N, Buchanan WW, Goldsmith CH, Campbell J, Stitt LW. Validation study of WOMAC: a health status instrument for measuring clinically important patient relevant outcomes to antirheumatic drug therapy in patients with osteoarthritis of the hip or knee. J Rheumatol. 1988;15(12):1833-40.

13. Malathi R, Kothari S, Chattopadhyay A, Agrawal PK, Banerjee $U$, Sahu RK. Raised serum IL 6 and CRP in radiographic knee osteoarthritis in Eastern India. JMSR. 2017;5(5):2168792. DOl: 10.18535/jmscr/v5i5.73.

14. Ayral X, Pickering EH, Woodworth TG, Mackillop N, Dougados M. Synovitis: a potential predictive factor of structural progression of medial tibiofemoral knee osteoarthritisresults of a 1 year longitudinal arthroscopic study in 422 patients. Osteoarthritis Cartilage. 2005;13(5):361-7. DOI: 10.1016/j.joca.2005.01.005.

15. Smith JW, Martins TB, Gopez E, Johnson T, Hill HR, Rosenberg T D. Significance of C-reactive protein in osteoarthritis and total knee arthroplasty outcomes. Ther Adv Musculoskelet Dis. 2012;4(5):315-25. DOI: 10.1177/1759720X12455959.

16. Lotz M, Martel-Pelletier J, Christiansen C, Brandi ML, Bruyère 0 , Chapurlat $R$, et al. Value of biomarkers in osteoarthritis: current status and perspectives. Ann Rheum Dis. 2013;72(11):1756-63. DOI: 10.1136/annrheumdis-2013-203726.
17. Spector TD, Hart DJ, Nandra D, Doyle DV, Mackillop N, Gallimore JR, Pepys MB. Low-level increases in serum Creactive protein are present in early osteoarthritis of the knee and predict progressive disease. Arthritis Rheum. 1997;40(4):723-7. DOl: 10.1002/art.1780400419.

18. Arendt-Nielsen L, Eskehave TN, Egsgaard LL, Petersen KK, Graven-Nielsen T, Hoeck HC, et al. Association between experimental pain biomarkers and serologic markers in patients with different degrees of painful knee osteoarthritis. Arthritis Rheumatol, 2014;66(12):3317-26. DOI: 10.1002/ art.38856.

19. Sanchez-Ramirez DC, van der Leeden M, van der Esch M, Gerritsen M, Roorda LD, Verschueren S, et al. Association of serum C-reactive protein and erythrocyte sedimentation rate with muscle strength in patients with knee osteoarthritis. Rheumatology (Oxford). 2012;52(4):727-32. DOI: 10.1093/rheumatology/kes366.

20. Zhu Z, Jin X, Wang B, Wluka A, Antony B, Laslett L, et al. Cross-sectional and longitudinal associations between serum levels of high-sensitivity C-reactive protein, bone marrow lesions, and knee pain in patients with knee osteoarthritis. Arthritis Care Res (Hoboken). 2016;68(10):1471-77. DOI: 10.1002/acr.22834.

21. Roddy E, Doherty M. Gout and osteoarthritis: a pathogenetic link? Joint Bone Spine. 2012;79(5):425-7. DOl: 10.1016/j. jbspin.2012.03.013.

22. Ma CA, Leung YY. Exploring the link between uric acid and osteoarthritis. Front Med (Lausanne). 2017;4:225. DOI: 10.3389/fmed.2017.00225.

23. Martinon F, Pétrilli V, Mayor A, Tardivel A, Tschopp J. Goutassociated uric acid crystals activate the NALP3 inflammasome. Nature. 2006;440(7081):237. D0I: 10.1038/ nature04516.

24. Denoble AE, Huffman KM, Stabler TV, Kelly SJ, Hershfield MS, McDaniel GE, et al. Uric acid is a danger signal of increasing risk for osteoarthritis through inflammasome activation. Proc Natl Acad Sci U S A. 2011;108(5):2088-93. DOI: 10.1073/pnas. 1012743108.

25. Bonora E, Targher G, Zenere MB, Saggiani F, Cacciatori $\mathrm{V}$, Tosi $\mathrm{F}$, et al. Relationship of uric acid concentration to cardiovascular risk factors in young men. Role of obesity and central fat distribution. The Verona Young Men Atherosclerosis Risk Factors Study. Int J Obes Relat Metab Disord. 1996;20(11):975-80.

26. Lyngdoh T, Marques-Vidal P, Paccaud F, Preisig M, Waeber $G$, Bochud $M$,et al. Elevated serum uric acid is associated with high circulating inflammatory cytokines in the populationbased Colaus study. PLoS One. 2011;6(5):e19901. DOI: $10.1371 /$ journal. pone.0019901.

27. Wangkaew S, Kasitanon N, Hongsongkiat S, Tanasombat C, Sukittawut W, Louthrenoo W, et al. A comparative study of serum and synovial fluid levels of uric acid between patients with gout and other arthritides. J Med Assoc Thai. 2014;97(7):679-85.

28. Billiet L, Doaty S, Katz JD, Velasquez MT. Review of hyperuricemia as new marker for metabolic syndrome. ISRN Rheumatol. 2014;2014:852954. DOI: 10.1155/2014/852954.

29. Cho HJ, Chang CB, Yoo JH, Kim SJ, Kim TK. Gender differences in the correlation between symptom and radiographic severity in patients with knee osteoarthritis. Clin Orthop Relat Res. 2010;468(7):1749-58. DOI: 10.1007/s11999-0101282-z.

30. Neumann G, Hunter D, Nevitt M, Chibnik LB, Kwoh K, Chen $\mathrm{H}$, et al. Location specific radiographic joint space width 
for osteoarthritis progression. Osteoarthritis Cartilage. 2009;17(6):761-5. DOl: 10.1016/j.joca.2008.11.001.

31. Mazzuca SA, Brandt KD, Katz BP. Is conventional radiography suitable for evaluation of a disease-modifying drug in patients with knee osteoarthritis? Osteoarthritis Cartilage. 1997;5(4):21726. DOI: 10.1016/S1063-4584(97)80017-9.

32. Altman RD, Fries JF, Bloch DA, Carstens J, Cooke TD, Genant $\mathrm{H}$, et al. Radiographic assessment of progression in osteoarthritis. Arthritis Rheum. 1987;30(11):1214-25. DOI: 10.1002/art.1780301103.

33. Conrozier T, Favret $\mathrm{H}$, Mathieu P, Piperno M, Provvedini D, Taccoen $A$, et al. Influence of the quality of tibial plateau alignment on the reproducibility of computer joint space measurement from Lyon schuss radiographic views of the knee in patients with knee osteoarthritis. Osteoarthritis Cartilage. 2004;12(10):765-70. DOI: 10.1016/j.joca.2004.06.003.

34. Altman R, Brandt K, Hochberg M, Moskowitz R, Bellamy $N$, Bloch DA, .et al. Design and conduct of clinical trials in patients with osteoarthritis: recommendations from a task force of the Osteoarthritis Research Society: results from a workshop. Osteoarthritis Cartilage. 1996;4(4):217-43. DOI: 10.1016/S1063-4584(05)80101-3.

35. Cicuttini F, Hankin J, Jones G, Wluka A. Comparison of conventional standing knee radiographs and magnetic resonance imaging in assessing progression of tibiofemoral joint osteoarthritis. Osteoarthritis Cartilage. 2005;13(8):722-7. DOI: 10.1016/j.joca.2005.04.009.

36. Cicuttini F, Hankin J, Jones G, Wluka A. Comparison of conventional standing knee radiographs and magnetic resonance imaging in assessing progression of tibiofemoral joint osteoarthritis. Osteoarthritis Cartilage. 2005;13(8):722-7. DOI: 10.1016/j.joca.2005.04.009.

37. Noori-Zadeh A, Bakhtiyari S, Khooz R, Haghani K, Darabi S. Intra-articular ozone therapy efficiently attenuates pain in knee osteoarthritic subjects: A systematic review and metaanalysis. Complement Ther Med. 2019;42:240-7. DOI: 10.1016/j.ctim.2018.11.023.

38. Arias-Vázquez PI, Tovilla-Zárate CA, Bermudez-Ocaña DY, Legorreta-Ramírez BG, López-Narváez ML. Eficacia de las infiltraciones con ozono en el tratamiento de la osteoartritis de rodilla vs. otros tratamientos intervencionistas: revisión sistemática de ensayos clínicos. Rehabilitación. 2019;53(1):43-55. DOI: 10.1016/j.rh.2018.11.001.

39. Sconza C, Respizzi S, Virelli L, Vandenbulcke F, lacono F, Kon $E$, et al. Oxygen-ozone therapy for the treatment of knee osteoarthritis: a systematic review of randomized controlled trials. Arthroscopy. 2020;36(1):277-86.

40. Oliviero A, Giordano L, Maffulli N. The temporal effect of intraarticular ozone injections on pain in knee osteoarthritis. $\mathrm{Br}$ Med Bull. 2019;132(1):33-44. DOI: 10.1093/bmb/ldzO28. 